\title{
Metabolic and endocrine events at the time of the first feed of human milk in preterm and term infants
}

\author{
A. LUCAS, S. R. BLOOM, AND A. AYNSLEY-GREEN
}

From the University Department of Paediatrics, Oxford, and Hammersmith Hospital

SUMmaRY The first feed of breast milk given to a group of 12 term infants was previously shown to increase the levels of blood glucose and plasma insulin, growth hormone (GH), gastrin, and enteroglucagon. We have now studied the effects of the first feed of breast milk in two similar groups of preterm infants, to compare the results with those obtained for the term infant. One group of 8 preterm infants received a bolus $(2 \cdot 5 \mathrm{ml} / \mathrm{kg})$ of breast milk via a nasogastric tube; the other group of 5 infants received a continuous intragastric infusion $(2.5 \mathrm{ml} / \mathrm{kg}$ per hour) of breast milk. No change occurred in the concentrations of blood glucose, lactate, pyruvate, or ketone bodies, or in plasma insulin, GH, pancreatic glucagon, or enteroglucagon in either the 'bolus fed' or the 'infusion fed' group of preterm infants. Thus the marked metabolic and endocrine changes in term infants after the first feed do not occur in preterm infants with standard methods of feeding.

We have shown previously that term babies suffering from moderately severe respiratory distress show an increase in blood glucose, associated with a rise in plasma insulin, growth hormone $(\mathrm{GH})$, gastrin, and enteroglucagon after the first feed (AynsleyGreen et al., 1977). This suggests that digestion and absorption, as well as several hormone systems, are functionally active at birth in the term infant.

To define the metabolic and endocrine effects of standard feeding practices in the preterm infant, we measured blood levels of several metabolites and hormones before and after the first feed of breast milk in a group of infants fed by an intragastric bolus, and before and during the first feed in a group of infants fed by continuous intragastric infusion.

\section{Patients and feeding procedure}

Patients. 15 preterm infants were studied with the approval of the ethical committee. The infants had been admitted to the special care baby unit because of prematurity. All had weights appropriate for gestational age. All had umbilical catheters in situ for clinical monitoring purposes. They were nursed either in incubators at environmental temperatures appropriate for their gestation and weight (Hey and Katz, 1970), or under radiant heaters with skin temperature servo controlled to $36 \cdot 5^{\circ} \mathrm{C}$. At the time of the study no baby had a rectal temperature

Received 18 January 1978 below $36^{\circ} \mathrm{C}$. In all arterial $\mathrm{pH}$ was $>7 \cdot 20$ throughout the study. $\mathrm{PaO}_{2}$ was maintained between 60 and $90 \mathrm{mmHg}(8$ and $12 \mathrm{kPa}$ ). One baby required resuscitation for apnoea 15 minutes after the first feed and was excluded from the study. The clinical condition of the remaining 14 infants did not change during the study. The infants were randomly divided into two groups, one receiving a bolus of breast milk and the other a continuous intragastric infusion of breast milk.

In the bolus fed group, 8 infants were studied. The mean birthweight was $1290 \mathrm{~g}$ (range 960 to $1740 \mathrm{~g}$ ), and the mean gestational age from maternal dates and paediatric assessment (Farr score) was 30 weeks (range 28 to 33 weeks). All 8 babies had respiratory distress, 7 requiring oxygen via a head box, one requiring assisted ventilation via an endotracheal tube.

In the infusion fed group, 6 infants were initially studied, but one infant was excluded because he regurgitated his feed. The mean birthweight of the remaining 5 infants was $1520 \mathrm{~g}$ (range 1100 to $1770 \mathrm{~g}$ ) and a mean gestational age of 30 weeks (range 28 to 32 weeks). 3 of the 5 babies had respiratory distress, requiring continuous positive airways pressure through an endotracheal tube. The 2 other infants had no respiratory problems.

Feeding procedure. The first feed was given between 3 and 6 hours of age. None of the infants had received intravenous dextrose. A nasogastric tube was inserted 
into the stomach and the contents aspirated 30 minutes before the feed. The bolus fed infants received $2.5 \mathrm{ml} / \mathrm{kg}$ pooled boiled mature breast milk given by gravity for a 3-5-minute period via the nasogastric tube with the infant lying on the right side. Infusion fed infants received breast milk at a constant infusion rate of $2.5 \mathrm{ml} / \mathrm{kg}$ per hour via the nasogastric tube using a syringe pump.

After 55 minutes, the end of the study period, the stomach contents were aspirated and in no case was more than $25 \%$ of the original feed volume found to be present.

\section{Sampling and methods}

Blood samples were taken from the arterial catheter before the feed as described previously (AynsleyGreen et al., 1977) and, in the bolus fed group, at 5,25 , and 55 minutes after the feed: in the infusion fed group, samples were drawn at 25 and 55 minutes after the start of the infusion. Samples were assayed for blood glucose, lactate, pyruvate, $D$ - $\beta$-hydroxybutyrate, acetoacetate, plasma insulin, GH, pancreatic glucagon, and enteroglucagon (Aynsley-Green et al., 1977). Results were assessed for statistical significance by means of Student's $t$ tests.

\section{Results}

Blood glucose and other metabolites. The mean $( \pm$ SEM) fasting blood glucose concentration in the bolus fed group was $3.93 \pm 0.45 \mathrm{mmol} / 1(70 \cdot 81 \pm$ $8.11 \mathrm{mg} / 100 \mathrm{ml}$ ) and in the infusion fed group $3.08 \pm 0.62 \mathrm{mmol} / 1(55.50 \pm 11.17 \mathrm{mg} / 100 \mathrm{ml})$. In neither group was there a significant change in level with feeding. Fig. 1 shows, for comparison, the changes in blood glucose seen previously in term infants.

The mean fasting blood lactate and pyruvate concentrations were, for bolus fed infants, 1.98 \pm $0.31 \mathrm{mmol} / 1(17.83 \pm 27.9 \mathrm{mg} / 100 \mathrm{ml})$ and $0.12 \pm$ $0.01 \mathrm{mmol} / 1(1.06 \pm 1.09 \mathrm{mg} / 100 \mathrm{ml})$ respectively, and for infusion fed infants, $2 \cdot 12 \pm 1 \cdot 00$ $\mathrm{mmol} / \mathrm{l}(19 \pm 9 \mathrm{mg} / 100 \mathrm{ml})$ and $0 \cdot 18 \pm 0 \cdot 06$ $\mathrm{mmol} / \mathrm{l}(1 \cdot 6 \pm 0.53 \mathrm{mg} / 100 \mathrm{ml})$ respectively. Thes: levels did not change with feeding. Table 1 shows. the lactate and pyruvate levels with feeding in pres? term babies, compared with the levels in term babies studied previously.

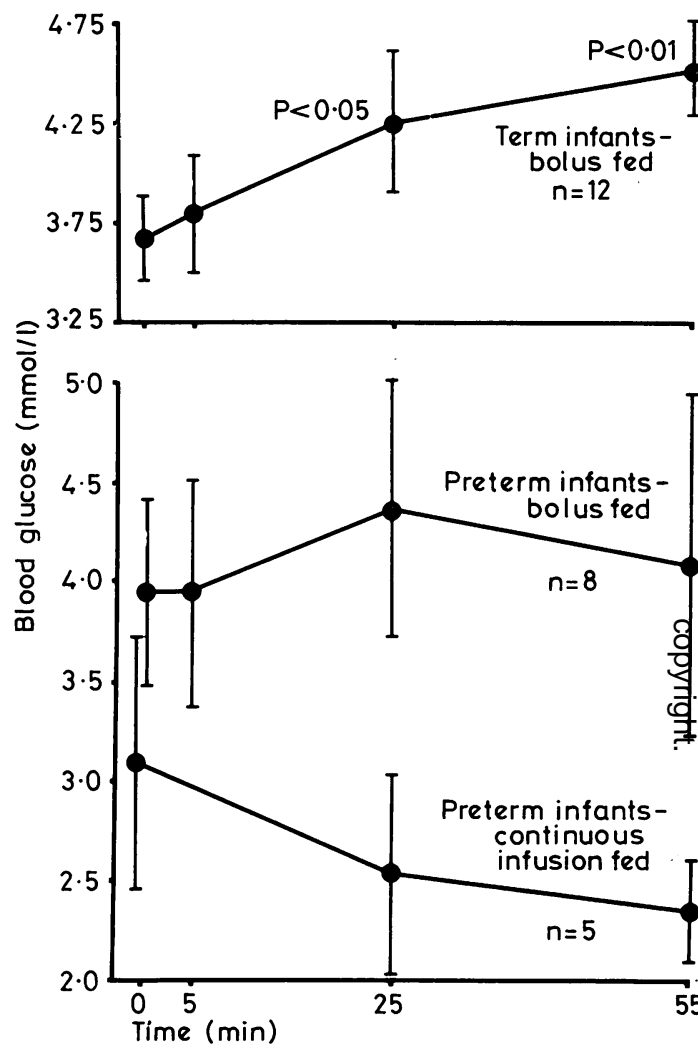

Fig. 1 Change in blood glucose after first feed of breast milk in term and preterm infants. Term infants were fed a $5 \mathrm{ml} / \mathrm{kg}$ bolus: preterm infants were fed either a $2.5 \mathrm{ml} / \mathrm{kg}$ bolus or a continuous intragastric infusion of $2.5 \mathrm{ml} / \mathrm{kg}$ per hour.

Table 1 Lactate and pyruvate concentrations before and after the first feed $(+S E M)$

\begin{tabular}{|c|c|c|c|c|c|}
\hline \multirow[t]{2}{*}{ Infants } & & \multicolumn{4}{|l|}{ Time (minutes) } \\
\hline & & 0 & 5 & 25 & 55 \\
\hline \multicolumn{6}{|l|}{ Term } \\
\hline Bolus fed $(n=12)$ & $\begin{array}{l}\text { Lactate (mmol/l) } \\
\text { Pyruvate (mmol/1) }\end{array}$ & $\begin{array}{l}2 \cdot 37 \pm 0.71 \\
0.20 \pm 0.04\end{array}$ & $\begin{array}{l}1 \cdot 73 \pm 0.34 \\
0.17 \pm 0.02\end{array}$ & $\begin{array}{l}2.02 \pm 0.43 \\
0.17 \pm 0.03\end{array}$ & $\begin{array}{l}1 \cdot 80 \pm 0.31 \\
0.17 \pm 0.03\end{array}$ \\
\hline \multicolumn{6}{|l|}{ Preterm } \\
\hline . & Pyruvate (mmol/l) & $0.12 \pm 0.01$ & $0.12 \pm 0.02$ & $0.13 \pm 0.03$ & $0.13 \pm 0.02$ \\
\hline Infusion fed $(n=5)$ & $\begin{array}{l}\text { Lactate }(\mathrm{mmol} / \mathrm{l}) \\
\text { Pyruvate }(\mathrm{mmol} / \mathrm{l})\end{array}$ & $\begin{array}{l}2.12 \pm 1.00 \\
0.18 \pm 0.06\end{array}$ & - & $\begin{array}{l}1.84 \pm 0.99 \\
0.18+0.06\end{array}$ & $\begin{array}{l}1.67 \pm 0.76 \\
0.20+0.06\end{array}$ \\
\hline & & $0.10 \pm 0.00$ & & $0.18 \pm 0.00$ & \\
\hline \multicolumn{6}{|c|}{ Conversion: SI to traditional units-Lactate: $1 \mathrm{mmol} / 1 \approx 9 \mathrm{mg} / 100 \mathrm{ml}$. Pyruvate: $1 \mathrm{mmol} / 1 \approx 8.8 \mathrm{mg} / 100 \mathrm{ml}$} \\
\hline
\end{tabular}


The mean fasting acetoacetate level in preterm babies before the first feed was $0.06 \pm 0.01 \mathrm{mmol} / \mathrm{l}$ in the bolus fed group and $0.06 \pm 0.01 \mathrm{mmol} / 1$ in the infusion fed group. There was no significant change with feeding in the two groups (Table 2).

The mean fasting $D-\beta$-hydroxybutyrate levels from 6 of the premature infants studied before the first feed were $0 \cdot 36 \pm 0 \cdot 02$. The levels were not measured during feeding.

Fig. 2 shows the mean fasting levels of acetoacetate, $D$ - $\beta$-hydroxybutyrate, and total ketones of all

Table 2 Acetoacetate concentrations before and after the first feed ( $\pm S E M)$

\begin{tabular}{|c|c|c|c|c|}
\hline \multirow[t]{2}{*}{ Infants } & \multicolumn{4}{|c|}{ Time (minutes) } \\
\hline & 0 & 5 & 25 & 55 \\
\hline \multicolumn{5}{|l|}{ Term } \\
\hline $\begin{array}{l}\text { Bolus fed } \\
(\mathrm{n}=12) \\
(\mathrm{mmol} / \mathrm{l})\end{array}$ & $\begin{array}{l}0.13 \\
\pm 0.02\end{array}$ & $\begin{array}{l}0.15 \\
\pm 0.04\end{array}$ & $\begin{array}{l}0.14 \\
\pm 0.03\end{array}$ & $\begin{array}{l}0.15 \\
\pm 0.02\end{array}$ \\
\hline $\begin{array}{l}\text { Preterm } \\
\text { Bolus fed } \\
(\mathrm{n}=8) \\
(\mathrm{mmol} / \mathrm{l})\end{array}$ & $\begin{array}{l}0.06 \\
\pm 0.01\end{array}$ & $\begin{array}{l}0.06 \\
\pm 0.02\end{array}$ & $\begin{array}{l}0.07 \\
\pm 0.03\end{array}$ & $\begin{array}{l}0.09 \\
\pm 0.04\end{array}$ \\
\hline $\begin{array}{l}\text { Infusion } \\
\text { fed }(\mathrm{n}=5) \\
(\mathrm{mmol} / \mathrm{l})\end{array}$ & $\begin{array}{l}0.06 \\
\pm 0.01\end{array}$ & - & $\begin{array}{l}0.06 \\
\pm 0.01\end{array}$ & $\begin{array}{l}0.06 \\
\pm 0.02\end{array}$ \\
\hline
\end{tabular}

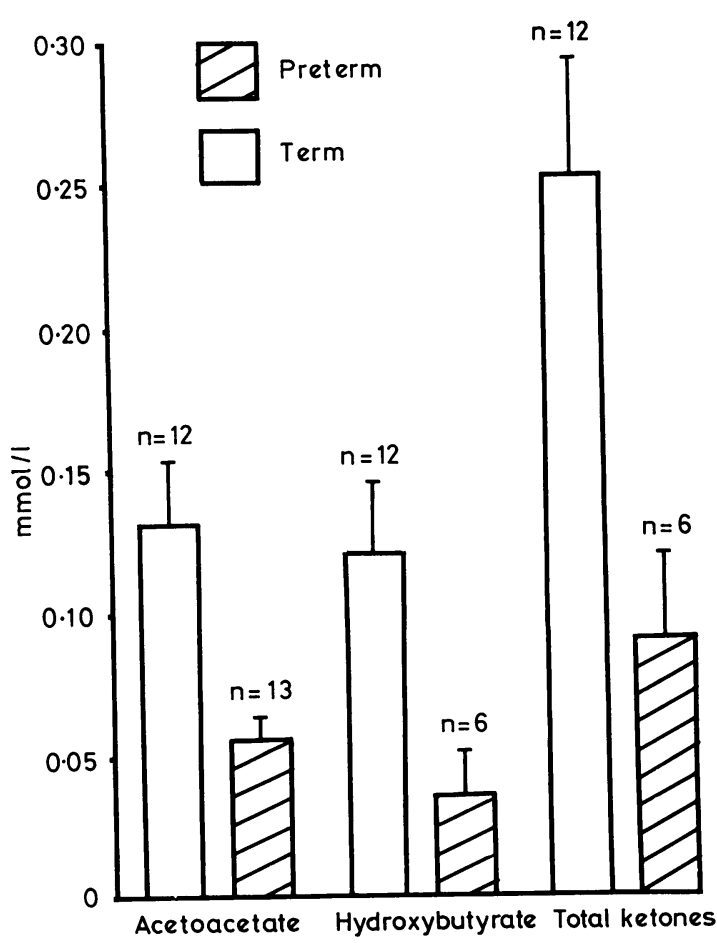

Fig. 2 Comparison of basal blood ketone values in term and preterm babies at 3-6 hours of age (just before first feed). the infants studied, compared with the levels described previously in term infants before the first feed: preterm infants had significantly lower ketone levels than term infants.

Plasma hormones. Mean basal plasma insulin concentration was $4.99 \pm 1.08 \mathrm{mU} / 1$ in the bolus fed group and $3.64 \pm 1.22 \mathrm{mU} / 1$ in the infusion fed group. These levels did not change significantly (by the paired $t$ test) with feeding in either group. However, comparison of the mean values from the two groups shows that, although there was no significant difference in basal insulin levels, the infusion fed group had a significantly lower insulin level $(\mathrm{P}<0.005)$ by 55 minutes than the bolus fed group. Fig. 3 compares plasma insulin levels with feeding in preterm babies with those found previously in term babies.

Plasma GH and enteroglucagon levels are available only in bolus fed preterm infants. Mean fasting plasma GH level was $27.7 \pm 5.7 \mu \mathrm{g} / \mathrm{l}$ and, in contrast to term infants previously studied, there was no change in concentrations with feeding although the basal levels were higher in preterm infants (Fig. 4). Mean fasting enteroglucagon level was $160 \pm 70 \mathrm{pg} / \mathrm{ml}$ (equivalent) and did not change with feeding, whereas term infants previously studied showed a rise in enteroglucagon 25 and 55 minutes after a feed (Table 3).

Mean fasting pancreatic glucagon concentrations were $34.3 \pm 10.4 \mathrm{pmol} / 1$ in the bolus fed preterm

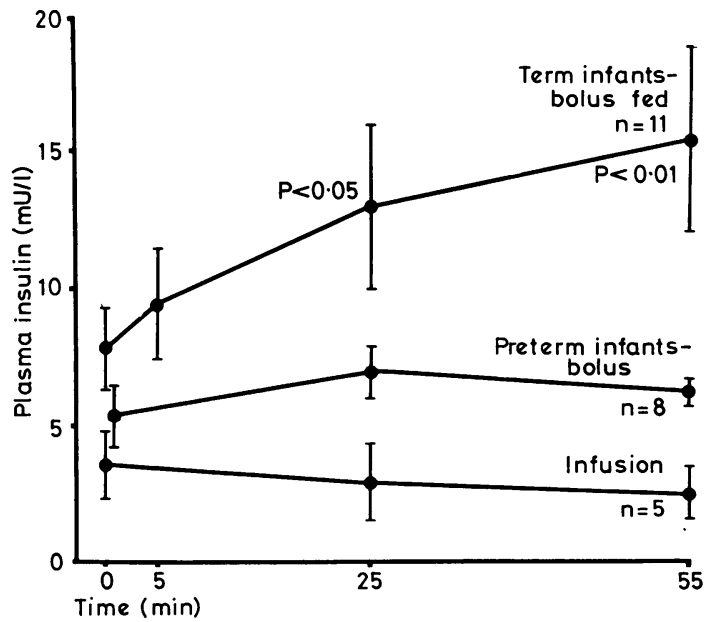

Fig. 3 Change in plasma insulin after first feed of breast milk in term and preterm infants. Term infants were fed a $5 \mathrm{ml} / \mathrm{kg}$ bolus: preterm infants were fed either a $2.5 \mathrm{ml} / \mathrm{kg}$ bolus or a continuous intragastric infusion of $2.5 \mathrm{ml} / \mathrm{kg}$ per hour. 
infants and $38.4 \pm 10.3 \mathrm{pmol} / \mathrm{l}$ in the infusion fed group. In neither group did the level change with feeding, and in this respect the preterm resembles the term infant (Table 4).

\section{Discussion}

There is little information on the metabolic and endocrine effects of conventional feeding practices

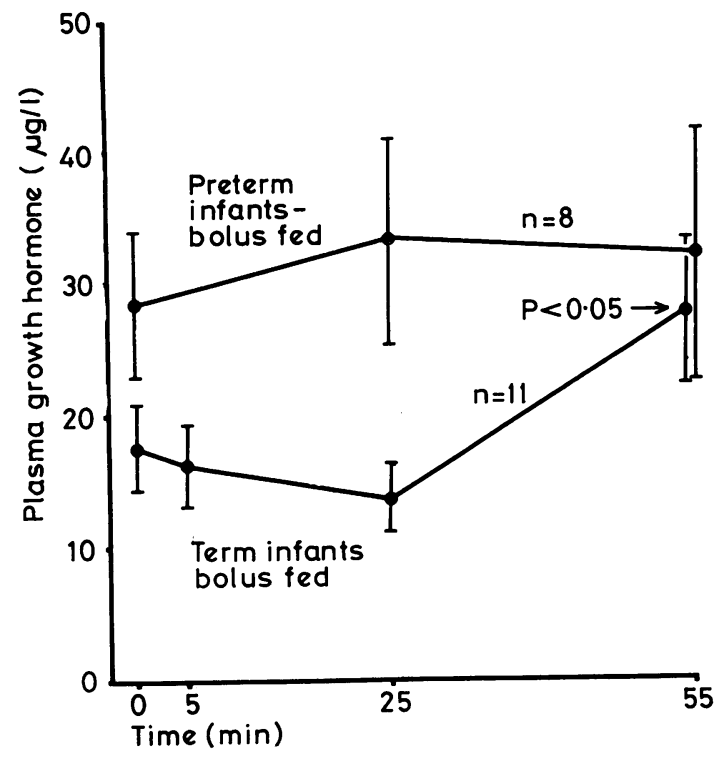

Fig. 4 Change in plasma growth hormone after first feed of breast milk in term and preterm infants. Term infants were fed a $5 \mathrm{ml} / \mathrm{kg}$ bolus, preterm infants a $2.5 \mathrm{ml} / \mathrm{kg}$ bolus.

Table 3 Plasma enteroglucagon concentrations $(\mathrm{pg} / \mathrm{ml}$ equivalent $)$ before and after the first feed $( \pm S E M)$

\begin{tabular}{lllll}
\hline \multirow{2}{*}{$\begin{array}{l}\text { Bolus fed } \\
\text { infants }\end{array}$} & \multicolumn{4}{l}{ Time (minutes) } \\
\cline { 2 - 5 } & 0 & 5 & 25 & 55 \\
\hline Term & $145 \pm 30$ & $243 \pm 51$ & $258 \pm 50$ & $305 \pm 65$ \\
$(\mathrm{n}=11)$ & & NS & $\mathbf{P}<0.05$ & $\mathbf{P}<0.05$ \\
$\begin{array}{c}\text { Preterm } \\
(\mathrm{n}=7)\end{array}$ & $160 \pm 70$ & $155 \pm 62$ & $157 \pm 67$ & $139 \pm 51$ \\
& & NS & NS & NS \\
\hline
\end{tabular}

Table 4 Plasma pancreatic glucagon (pmol/l) concentrations before and after the first feed $( \pm S E M)$

\begin{tabular}{lllll}
\hline $\begin{array}{l}\text { Preterm } \\
\text { infants }\end{array}$ & \multicolumn{4}{l}{ Time (minutes) } \\
\cline { 2 - 5 } & 0 & 5 & 25 & 55 \\
\hline Bolus fed & $34 \cdot 4 \pm 10 \cdot 4$ & $26 \cdot 4 \pm 4 \cdot 0$ & $37 \cdot 3 \pm 11 \cdot 4$ & $40 \cdot 4 \pm 11 \cdot 5$ \\
$(n=7)$ & $N S$ & NS & NS \\
$\begin{array}{llll}\text { Infusion fed } \\
(n=5)\end{array}$ & $38 \cdot 4 \pm 10 \cdot 3$ & - & $37 \cdot 4 \pm 8 \cdot 4$ & $46 \cdot 0 \pm 14 \cdot 3$ \\
& & & NS & NS \\
\hline
\end{tabular}

in newborn infants. In our unit infants requiring intensive care are usually fed on the first day of life. with $60 \mathrm{ml} / \mathrm{kg}$ per day breast milk. Infants approaching term are fed 2 -hourly $(5 \mathrm{ml} / \mathrm{kg}$ per feed) whereas preterm infants are fed hourly, either with a bolus off breast milk $(2.5 \mathrm{ml} / \mathrm{kg}$ per feed) or with an intro gastric infusion of milk at the rate of $2.5 \mathrm{ml} / \mathrm{kg}$ pew. hour. The purpose of this paper is to examine the metabolic and endocrine consequences of these standard feeding regimens for preterm infants an $\mathrm{e}^{\mathrm{B}}$ compare the results with those previously observe $\Phi$ by us in sick term infants.

Blood glucose and other intermediary metabolites. 10 is not clear why the glycaemic response to the firso feed of breast milk in term infants is not seen iff either bolus fed or infusion fed preterm infants. Ii no case was more than $25 \%$ of the original feet volume aspirated from the stomach at the end of the study, so that gastric pooling is an unlikely cause Failure of intestinal absorption is a more likely explanation, although a further possibility is thas the glycaemic effect of feeding was counterbalance by peripheral glucose uptake in these particula $\bar{B}$ preterm infants. Alternatively, the small feed volum $\Phi$ given to preterm infants $(2.5 \mathrm{ml} / \mathrm{kg})$ compared with. term infants $(5 \mathrm{ml} / \mathrm{kg})$ could account for the fif ference in response. If this is the case, then some important questions are raised concerning caing ventional feeding practices for preterm infants (see below).

It is interesting that no difference was found in the basal levels of blood glucose in term and preternæ infants at this stage in view of the findings $\mathrm{rf}$ Corn $\overrightarrow{\overline{\mathrm{O}}}$ blath and Reisner (1965) who showed lower levels i preterm infants.

Although many of the preterm infants in this study were suffering from conditions likely to cause hypoxia, mean blood lactate levels and lactate pyruvate ratios were not raised, suggesting adequate tissue oxygenation. The levels were similar to those found in the term infants.

There was no change in ketone body concentra tions (acetoacetate) with feeding in the preterm baby응 However, basal levels of ketones were substantially lower than those reported in the term baby (Aynsley을. Green et al., 1977). In newborn infants free fatty acids rise after birth as a result of increased lipolysis (Persson and Gentz, 1966). In turn, these fatty acids are in part metabolised to ketones which rapidl స్ట reach very high levels in the first few days of life (Melichar et al., 1965; Persson and Gentz, 1966) Ketone bodies have been demonstrated to be impor tant substrates for cerebral metabolism and are actively taken up by the neonatal brain (Hawkins $e$ to al., 1971; Kraus et al.v 1974: Settergren et al. 
1976). Melichar et al. (1967) have reported higher rates of lipolytic activity and higher levels of ketones in preterm infants than in term infants in the first $\mathbf{1 2}$ hours of life. In view of these findings it is surprising that in the preterm infants we studied, at 3-6 hours age, the ketones were so much lower than in the term infants that we had studied previously at this age. Our findings are difficult to interpret in the absence of data on free fatty acids, but imply either increased ketone consumption or decreased ketogenic ability. If the latter is the case, it is possible that in certain preterm babies lipolytic activity lags for a few hours before accelerating and exceeding the rate of lipolysis in the term baby; thus the preterm baby might, for a few hours after birth, be at greater risk than the term baby in terms of providing substrates for brain metabolism.

Plasma hormones. Several investigators have studied the effect of pharmacological stimuli on the release of pancreatic islet cell hormones and of $\mathrm{GH}$ in preterm infants (Reitano et al., 1971; Ponté et al., 1972; Falorni et al., 1975a, b): however, the hormonal effects of the physiological stimulus of an enteral feed given to the preterm infant has received little attention. In this study the insulin response to enteral feeding, seen in term infants, was not found in preterm infants. This could have been owing to a failure to increase blood glucose. Pancreatic glucagon did not change with the first feed and in this respect the preterm infant resembles the term infant.

The lack of enteroglucagon response in the preterm infant, despite the presence of foodstuff in the lumen of the small bowel (which has been demonstrated to be a stimulus to enteroglucagon release: Böttger et al., 1973; Holst et al., 1976), contrasts with the marked rise in enteroglucagon seen in term infants after the first feed. This difference between term and preterm infants may be dose related (because of the smaller feed volume given to preterm infants), or due to a functional immaturity of gastrointestinal hormone release in preterm infants.

Fasting plasma GH levels at 3-6 hours of age, were higher in preterm infants than in the term infants, and in contrast to the latter, the levels were unaffected by the first feed. Higher levels of GH in preterm infants than in term infants have been reported by Cornblath et al. (1965), but only after 48 hours of age. The lack of increase after feeding could again be owing to a failure to increase blood glucose.

\section{Conclusion}

The clinical and physiological significance of the lack of glycaemic and hormonal effects of the first feed in preterm infants is unknown. Further studies are needed to define both the development of feeding responses in these infants, and the stage at which they respond to enteral feeding in a similar way to term infants. The absent metabolic responses in preterm infants may represent either physiological differences between term and preterm infants or, alternatively, the differences may relate to the smaller feed volumes given to preterm infants. If the latter is the case, then it needs to be determined if the small volume, frequent feeding regimens, conventionally used with such infants, fail to cause the phasic metabolic and hormone changes which can be expected during physiological feeding and fasting in term infants. It is possible that the preterm infant's ability to adapt to extrauterine nutrition may be affected by the failure of conventional feeding practices to induce cyclical metabolic and endocrine changes.

We thank Prof. J. P. M. Tizard and Dr D. H. Williamson for advice and encouragement, the nursing staff of the special care baby unit for help, and Mrs E. Harris, Mrs V. Ilic, and Mrs P. Jenkins for technical assistance. A. L. was the recipient of a Wellcome Trust research fellowship.

\section{References}

Aynsley-Green, A., Bloom, S. R., Williamson, D. H., and Turner, R. C. (1977). Endocrine and metabolic response in the human newborn to the first feed of breast milk. Archives of Disease in Childhood, 52, 291-295.

Böttger, I., Dobbs, R., Faloona, G. R., and Unger, R. H. (1973). The effects of triglyceride absorption upon glucagon, insulin and gut-glucagon-Jike immunoreactivity. Journal of Clinical Investigation, 52, 2532-2541.

Cornblath, M., Parker, M. L., Reisner, S. H., Forbes, A. E., and Daughaday, W. H. (1965). Secretion and metabolism of growth hormone in premature and full-term infants. Journal of Clinical Endocrinology and Metabolism, 25, 209-218.

Cornblath, M., and Reisner, S. H. (1965). Blood glucose in the neonate and its clinical significance. New England Journal of Medicine, 273, 378-381.

Falorni, A., Massi-Benedetti, F., Gallo, S., and Romizi, S. (1975a). Levels of glucose in blood and insulin in plasma and glucagon response to arginine infusion in low birth weight infants. Pediatric Research, 9, 55-60.

Falorni, A., Massi-Benedetti, F., Gallo, G., and Trabalza, N. (1975b). Blood glucose, serum insulin and glucagon response to arginine in premature infants. Biology of the Neonate, 27, 271-278.

Hawkins, R. A., Williamson, D. H., and Krebs, H. A. (1971). Ketone-body utilisation by adult and suckling rat brain in vivo. Biochemical Journal, 122, 13-18.

Hey, E. N., and Katz, G. (1970). The optimum thermal environment for naked babies. Archives of Disease in Childhood, 45, 328-334.

Holst, J. J., Christiansen, J., and Kühl, C. (1976). The enteroglucagon response to intrajejunal infusion of glucose, triglycerides, and sodium chloride, and its relation to jejunal inhibition of gastric acid secretion in man. Scandinavian Journal of Gastroenterology, 11, 297-304. 
Kraus, H., Schlenker, S., and Schwedesky, D. (1974). Developmental changes of cerebral ketone body utilisation in human infants. Hoppe-Seylers Zeitschrift für physiologische Chemie, 355, 164-170.

Melichar, V., Drahota, Z., and Hahn, P. (1965). Changes in blood levels of acetoacetate and ketone bodies in newborn infants. Biology of the Neonate, 8, 348-352.

Melichar, V., Drahota, Z., and Hahn, P. (1967). Ketone bodies in the blood of full term newborns, premature and dysmature infants, and infants of diabetic mothers. Biology of the Neonate, 11, 23-28.

Persson, B., and Gentz, J. (1966). The pattern of blood lipids, glycerol, and ketone bodies during the neonatal period, infancy, and childhood. Acta paediatrica Scandinavica, 55, 353-362.

Ponté, C., Gaudier, B., Deconinck, B., and Fourlinnie, J. C. (1972). Blood glucose, serum insulin, and growth hormone response to intravenous administration of arginine in premature infants. Biology of the Neonate, 20, 262-269.

Reitano, G., Grasso, S., Distetano, G., and Messina, A흘 (1971). The serum insulin and growth hormone response: to arginine and arginine with glucose in the premature infant. Journal of Clinical Endocrinology and Metabolism? 33, 924-928.

Settergren, G., Lindblad, B. S., and Persson, B. (1976)음 Cerebral blood flow and exchange of oxygen, glucose ketone bodies, lactate, pyruvate, and amino acids in infants. Acta paediatrica Scandinavica, 65, 343-353.

Correspondence to Dr A. Lucas, Department of Paediatrics, John Radcliffe Hospital, Headington $\vec{\overrightarrow{ }}$ Oxford OX3 9DU. 